Original Article

\section{Evaluation of the effect of radioactive cobalt-60 and ultraviolet rays on Giardia lamblia infectivity to mice}

\author{
Ahmed Fikry ${ }^{1}$, Heba Aminou ${ }^{1}$, Ayman Ibrahim ${ }^{1}$, Rola Farid ${ }^{2}$, Hamssa Magdy ${ }^{1}$ \\ ${ }^{1}$ Medical Parasitology and ${ }^{2}$ Pathology Departments, Faculty of Medicine, Ain-Shams \\ University, Cairo, Egypt
}

\begin{abstract}
Background: Giardia lamblia is a flagellated unicellular eukaryotic micro-organism that commonly causes diarrheal disease worldwide. Although giardiasis is usually self-limited, it can develop into chronic and life-threatening disease. Most waterborne outbreaks (74.8\%) were associated with drinking water as Giardia cysts are known to be resistant to chlorine at concentrations typically applied for water treatment.

Objective: To evaluate the effect of radioactive cobalt-60 and $254 \mathrm{~nm}$ ultraviolet (UV) irradiation on infectivity of Giardia cysts to mice.

Material and Methods: The study was conducted using $60 \mathrm{BALB} / \mathrm{c}$ mice divided into 6 groups with 10 mice in each. Group 1 received Giardia cysts treated with cobalt-60 (dose $0.25 \mathrm{KGy}$ ). Group 2 received cysts exposed to UV irradiation (wave length $254 \mathrm{~nm}$ ). Groups 3-6 served as controls. Techniques used for evaluation of the infectivity of Giardia cysts included direct stool examination, duodenal aspiration with examination of the aspirate for the presence of Giardia cysts or trophozoites and histopathological examination of the small intestine of each mouse.

Results: Infectivity of Giardia cysts was reduced to $50 \%$ by experimental irradiation with cobalt- 60 and $20 \%$ by UV, as shown by histopathological examination.

Conclusion: Low dose radioactive cobalt-60 and $254 \mathrm{~nm}$ UV radiations may be used as a control measure to prevent giardiasis, and as a mean of water treatment; but further studies are recommended for employment of both methods together or using smaller doses of each, thus benefitting from them both with less side effects.
\end{abstract}

Key Words: Cobalt-60, Giardia lamblia, histopathology, UV rays.

Received: 5 March 2017, Accepted: 10 July 2017.

Corresponding Author: Heba Aminou, Tel.: +20-10-0155-0924, E-mail: hebaaminou74@hotmail.com.

ISSN: 1687-7942, Vol. 10, No. 1 \& 2.

\section{INTRODUCTION}

Giardia lamblia is the most common intestinal protozoan parasite causing diarrhea in children especially those with malnutrition or immunodeficiency. The prevalence of giardiasis is $2-7 \%$ in industrialized countries and $40 \%$ in developing countries. In studies to assess the frequency of intestinal parasitic infection in Egypt, Giardia lamblia was recorded in $34.3 \%$ of stool samples by IFAT in a report from Menoufia governorate ${ }^{[1]}$; and $37 \%$ of water samples from different districts in Alexandria city also by flow cytometry ${ }^{[2]}$. A more recent report from greater Cairo recorded $26 \%$ infectivity ${ }^{[3]}$.

Although giardias is usually self-limited, it can develop into chronic and life-threatening disease. Chronic giardiasis in early childhood has been significantly associated with malnutrition disorders ${ }^{[4]}$. In the United States, analysis data on all giardiasis outbreaks (reported to the Centers for Disease Control from 1971 to 2011) showed 242 outbreaks, affecting approximately 41000 persons of whom $74.8 \%$ resulted from waterborne transmission. Most of these waterborne outbreaks were associated with drinking water, followed by recreational water $(18.2 \%)^{[5]}$.
Of note, Giardia cysts are known to be resistant to chlorine at concentrations typically applied for water treatment ${ }^{[6]}$. Disinfection using irradiation technology is of growing interest in the food and water industry being very effective against many organisms ${ }^{[7]}$. In addition, ionizing radiation has more advantages over deficiencies of chemical processes. Ionizing radiation showed ability for converting non-biodegradable substances to more readily degradable ones without leaving residues which is why it is called clean technology ${ }^{[8]}$.

There are no preparations for proper prophylaxis against giardiasis in spite of the numerous sources of infection with G. lamblia, and the preventive use of medications could not be recommended, except for highly endemic areas ${ }^{[9]}$. Current efforts are focused on finding new alternatives to chemical treatment, such as irradiation using UV rays ${ }^{[10]}$ and cobalt $60^{[11]}$. The high energy rays of irradiation cause direct damage to the DNA of living organisms inducing cross-linkages and other changes that render an organism unable to grow or reproduce. Additional damage to DNA of organisms is indirectly produced by the interaction of rays with intercellular water molecules generating transient free radicals $^{[12]}$. 
Since the early nineties, cobalt-60, a type of gamma radiation, has been used on food to control infectivity of several parasites as Paragonimus westermani ${ }^{[13]}$, Metagonimus yokogawai ${ }^{[14]}$, Eimeria tenella ${ }^{[15]}$, Toxoplasma gondii ${ }^{[16]}$, Angiostrongylus cantonensis ${ }^{[17]}$, Taenia solium $^{[18]}$, Clonorchis sinensis ${ }^{[19]}$, Cryptosporidium parvum $^{[20]}$, Ascaris lumbricoides ${ }^{[21]}$, Trypanosoma cruzi $^{[22]}$ and Echinococcus granulosus ${ }^{[23]}$. UV irradiation usage for the disinfection of drinking water was first applied in 1910 in Marseille. After that, UV radiation gained interest and during the 1980s, it has been largely used in Europe for the disinfection of drinking water; in some cases, it has been used to replace chlorination ${ }^{[24]}$.

Many studies have been made to investigate the effect of UV irradiation on food items. It diminished Salmonella species as well as Escherichia coli on fruits and vegetables ${ }^{[25]}$. For blood transfusion, UV treatment can also be an effective blood disinfection method against Trypanosoma cruzi ${ }^{[26]}$ and Leishmania donovani ${ }^{[27]}$. It can also be used against Cryptosporidium parvum ${ }^{[28]}$ and soil nematodes $^{[29]}$. For disinfections against contamination with Toxoplasma gondii cysts or oocysts one minute ultraviolet exposure inhibits tachyzoite replication and cyst conversion without diminishing host humoral-mediated immune response ${ }^{[30]}$. Concerning safety, a study carried by Kim et al. ${ }^{[31]}$ assured the safe use of radiation and relieved the general anxiety about exposure to low-dose radiation. Moreover, Koca et al. ${ }^{[32]}$ found that lack of acute adverse effects and low cost, seem to make radiotherapy one of the safest and cheapest treatment modality.

The present case control experimental study was conducted to evaluate the effect of radioactive cobalt- 60 and $254 \mathrm{~nm}-\mathrm{UV}$ irradiation on infectivity of $G$. lamblia cysts to mice, and examining their ability to reduce the cysts infectivity.

\section{MATERIALS AND METHODS}

Giardia cysts collection: Stool samples were collected from outpatients and inpatients attending laboratories of Ain Shams and Cairo University hospitals, Cairo, Egypt, with bias to patients with symptoms suggesting giardiasis. Samples were collected in clean, dry and labeled plastic containers and were examined in the Parasitology Research and Diagnostic Laboratory Unit at Faculty of Medicine, Ain Shams University, Cairo, Egypt to detect positive cases for giardiasis.

Purified Giardia cysts treatment: Stored samples of Giardia cysts were concentrated and purified ${ }^{[33,34]}$, then divided into 3 equal parts for irradiation with cobalt-60, irradiation with UV, and the third part was kept without radiation. All samples were preserved at $4^{\circ} \mathrm{C}$.

Cobalt-60 irradiations: Before irradiation, the sample was brought to room temperature in an open 55-mm glass
Petri dish. In the Medical Oncology Department, Ain Shams University, Cairo, Egypt, the sample was subjected to a direct field beam of radioactive cobalt-60 in a dose of $0.25 \mathrm{KGy}$, which gave an intensity of $1.25 \mathrm{MeV}$ at a distance of $60 \mathrm{~cm}$ on an area of $20 \times 20 \mathrm{~cm}$ with 0.5 bolus for $25 \mathrm{~min}^{[35]}$.

Ultraviolet radiation: The sample was put in a Petri dish ( $8.5 \mathrm{~cm}$ diameter) that was used as the static reaction vessel. The cysts were counted using a haemocytometer and diluted in physiological saline. The cyst preparations were assessed qualitatively for cyst aggregation by microscopy. The absorbance and percentage transmission of the suspension at $254 \mathrm{~nm}$ were measured at temperature $4.2^{\circ} \mathrm{C}$, exposure time 120 seconds and $20 \mathrm{~mJ} \mathrm{~cm}{ }^{2[36]}$.

Experimental infection of $B A L B / c$ mice with G. lamblia cysts: Sixty male BALB/c mice, aged 4-8 weeks old and weighing 25-40 gm, were obtained from the animal house of the National Research Center, Cairo, Egypt and were caged in the medical research center animal house, 2-3 mice per cage ${ }^{[37]}$. The mice were proven free of giardiasis by microscopically examining their stool on three consecutive days. The animals were divided into 6 groups each composed of 10 mice: group 1 infected with a suspension of human derived Giardia cysts irradiated with cobalt- $60^{[35]}$; group 2 infected with a suspension of human derived Giardia cysts irradiated with $254 \mathrm{~nm}-\mathrm{UV}$ rays ${ }^{[38]}$; group 3 infected with human derived non-treated Giardia cysts; group 4 non-infected mice, received water irradiated with 0.25 KGy of cobalt-60; group 5 non-infected mice, received water irradiated with $254 \mathrm{~nm}-\mathrm{UV}$ rays; group 6 noninfected mice, received non-treated water. The mice were inoculated orally by $0.2 \mathrm{ml}$ suspension, for each mouse, containing $1 \times 10^{6}$ cysts using an orogastric gavage, after overnight fasting ${ }^{[39]}$.

Parameters for evaluation of the infectivity of G. lamblia cysts: Fecal pellets were collected daily from each cage, starting from day 9 post inoculation ${ }^{[40]}$ and examined microscopically. If cysts were detected, the animals were individually placed in separate cages and their stool pellets were re-examined. All stool pellets from individually housed mice were examined microscopically over a 24-h period till day 12 .

All mice were sacrificed on day 21 post infection and duodenal aspiration was done. The aspirate was examined for Giardia cysts or trophozoites. Then, mice small intestines were opened by longitudinal $\operatorname{slit}^{[41]}$ and parts of the small intestine were preserved in $10 \%$ formalin solution for further hematoxylin and eosin (H\&E) staining and histopathological examination ${ }^{[42,43]}$.

Histopathological examination of small intestine: Small intestinal punch biopsy specimens were fixed, dehydratedand embedded in paraffin wax. Serial 
sections of 5 micron thickness were stained with H\&E. Histopathological evaluation was modified from Oberhuber and Stolte ${ }^{[44]}$. In all groups, sections were thoroughly examined to determine giardiasis, and confirmed by presence of sickle shaped trophozoites attached to surface epithelial cells or free within the mucus layer. The density of colonization was estimated semi-quantitatively $(0 ;+: 1-10$; ++ : 10-30; +++: >30). Inflammation was assessed semiquantitatively by estimating the quantity of inflammatory cells present in the lamina propria in random high power microscopic fields. Score $0=$ comparable to uninfected control (group 6); score $1=$ slightly increased intensity of inflammation; score 2 = moderate increase in intensity of inflammation; and score $3=$ severe inflammation compared to score 2 . The degree of villous flattening was assessed semi-quantitatively. Grade 0 represented normal villi; grade 1 was defined as mild villous flattening; grade II represented short blunted villi; and grade III represented subtotal villous flattening. The results were expressed as the number of intra epithelial lymphocytes for each 100 epithelial cells. Lymphoid follicles were defined as an aggregation of lymphocytes with or without germinal center $^{[44]}$.

Statistical analysis: For data management and analysis, the collected data was revised, coded, tabulated and introduced to a PC using statistical package for Social Science (SPSS 15.0.1 for windows; SPSS Inc, Chicago, IL, 2001). Data were presented and suitable analysis was done according to the type of data obtained for each parameter. For descriptive statistics, frequency and percentage of nonnumerical data was used. For analytical statistics, Fishers exact test was used to examine the relationship between two qualitative variables when the expected count was less than 5 in more than $20 \%$ of cells.

Ethical consideration: An informed consent was taken from all patients before taking stool samples. The study was approved by the Research Ethics Committee, Faculty of Medicine, Ain Shams University. Ethical guidelines for experimental animals were considered aiming to alleviate or minimize potential pain, suffering, or distress and enhance the welfare of the animals used.

\section{RESULTS}

Direct stool examination (Table 1 and Figure 1): In group 1 , one mouse (10\%) was infected on day 11 and remained infected till day 21 . In group 2 , all mice $(0 \%)$ were non-infected all through the 21 days. In group 3 , eight mice $(80 \%)$ were infected on day 10 and by day 21 all 10 mice $(100 \%)$ were infected. In groups $(4,5$ and 6$)$, no mice $(0 \%)$ were infected all through the 21 days. All non-infected mice that received irradiated or non-irradiated water were not infected.

Duodenal aspiration (Table 2 and Figure 2): On day 21, microscopic examination of duodenal aspirates of group 1 showed trophozoites in four mice $(40 \%)$; in group 2 no trophozoites $(0 \%)$ were detected; in group 3 trophozoites were detected in all mice (100\%).

Histopathology (Table 3, Figures 3 and 4): Histopathological examination of mice intestines revealed no trophozoites in the non-infected experimental control groups 4, 5 and 6. Trophozoites were detected in all of group 3 mice $(100 \%)$ infected with non-irradiated Giardia cysts. Irradiation with cobalt 60 (group 1) or UV rays (group 2) reduced the percentage of infection to $50 \%(P=0.003)$ and $20 \%(P=0.001)$ respectively (Table $3)$. The intensity of colonization decreased from $(+++)$ in group 3 to $(++/+)$ in group 1 and to $(+)$ in group 2 $(P<0.001)$. The grade of inflammation due to infection with non-irradiated Giardia cysts (group 3) was $2.80 \pm 0.42$. Irradiation of Giardia cysts with Cobalt 60 in group 1 decreased inflammation $(1.70 \pm 0.67, P=0.0004)$. Irradiation of Giardia cysts with UV rays in group 2 did not significantly decrease intestinal inflammation $(2.4 \pm 0.52, P=0.739)$. The inflammatory response to Cobalt 60 was less intense than UV rays $(P=0.0179)$, and the grade of inflammation ranged from $1.30+0.15$ in group 4 , to $1.7 \pm 0.67$ in group $1(P=0.1449)$. The grade of inflammation due to UV rays ranged from $1.9 \pm 0.74$ in group 5 to $2.4 \pm 0.52$ in group $2,(P=0.0962)$. In the infected experimental groups 1,2 and 3 , the villus changes ranged from first degree mild flattening to second degree short blunted.

The percentage of villus change observed in group 3 infected with non-irradiated Giardia cysts significantly decreased when the cysts were irradiated with cobalt 60 in group $1(P=0.033)$. Irradiation with UV rays in group 2 did not significantly alter the villus changes. No difference in the villus architecture occurred when the cysts were irradiated with cobalt 60 in group 1 or UV rays in group 2 (Table 3 ). 
Evaluation of radiation effect on Giardia Fikry et al.

Table 1: Results of direct stool examination for Giardia cysts for groups 1, 2 and 3 (21 days after infection)

\begin{tabular}{|c|c|c|c|c|c|c|}
\hline & \multirow{2}{*}{$\begin{array}{l}\text { Positive } \\
\text { Number }\end{array}$} & \multirow{2}{*}{$\%$} & \multirow{2}{*}{$\begin{array}{l}\text { Negative } \\
\text { Number }\end{array}$} & \multirow{2}{*}{$\%$} & \multicolumn{2}{|c|}{ Fisher exact test } \\
\hline & & & & & $P$ value & Significance \\
\hline G1 & 1 & $10 \%$ & 9 & $90 \%$ & \multirow[b]{2}{*}{1} & \multirow[b]{2}{*}{ NS } \\
\hline G2 & 0 & $0 \%$ & 10 & $100 \%$ & & \\
\hline G1 & 1 & $10 \%$ & 9 & $90 \%$ & \multirow[b]{2}{*}{$<0.001$} & \multirow[b]{2}{*}{$\mathrm{S}$} \\
\hline G3 & 10 & $100 \%$ & 0 & $0 \%$ & & \\
\hline G2 & 0 & $0 \%$ & 10 & $100 \%$ & \multirow[b]{2}{*}{$<0.001$} & \multirow[b]{2}{*}{$\mathrm{S}$} \\
\hline G3 & 10 & $100 \%$ & 0 & $0 \%$ & & \\
\hline
\end{tabular}

Table 2: Results of duodenal aspirate examination for Giardia cysts for groups 1, 2 and 3 (21 days after infection)

\begin{tabular}{|c|c|c|c|c|c|c|}
\hline & \multirow{2}{*}{$\begin{array}{l}\text { Positive } \\
\text { Number }\end{array}$} & \multirow{2}{*}{$\%$} & \multirow{2}{*}{$\begin{array}{l}\text { Negative } \\
\text { Number }\end{array}$} & \multirow{2}{*}{$\%$} & \multicolumn{2}{|c|}{ Fisher exact test } \\
\hline & & & & & $P$ value & Significance \\
\hline G1 & 4 & $40 \%$ & 6 & $60 \%$ & \multirow[b]{2}{*}{0.087} & \multirow[b]{2}{*}{ NS } \\
\hline G2 & 0 & $0 \%$ & 10 & $100 \%$ & & \\
\hline G1 & 4 & $40 \%$ & 6 & $60 \%$ & \multirow[b]{2}{*}{$<0.011$} & \multirow[b]{2}{*}{$\mathrm{S}$} \\
\hline G3 & 10 & $100 \%$ & 0 & $0 \%$ & & \\
\hline G2 & 0 & $0 \%$ & 10 & $100 \%$ & \multirow[b]{2}{*}{$<0.001$} & \multirow[b]{2}{*}{$\mathrm{S}$} \\
\hline G3 & 10 & $100 \%$ & 0 & $0 \%$ & & \\
\hline
\end{tabular}

Table 3: Histopathological results of groups 1, 2 and 3 showing 2 parameters (trophozoite existence and villous changes)

\begin{tabular}{|c|c|c|c|c|c|c|c|c|c|c|c|c|}
\hline \multicolumn{7}{|c|}{ Giardia trophozoite } & \multicolumn{6}{|c|}{ Villus changes } \\
\hline & \multicolumn{2}{|c|}{ Positive } & \multicolumn{2}{|c|}{ Negative } & \multicolumn{2}{|c|}{$\begin{array}{c}\text { Fisher } \\
\text { exact test }\end{array}$} & \multicolumn{2}{|c|}{ Positive } & \multicolumn{2}{|c|}{ Negative } & \multicolumn{2}{|c|}{$\begin{array}{c}\text { Fisher } \\
\text { exact test }\end{array}$} \\
\hline & $\mathbf{N}$ & $\%$ & $\mathbf{N}$ & $\%$ & $P$ value & Sig. & $\mathbf{N}$ & $\%$ & $\mathbf{N}$ & $\%$ & $P$ value & Sig. \\
\hline G1 & 5 & $50 \%$ & 5 & $50 \%$ & \multirow{2}{*}{0.350} & \multirow{2}{*}{ NS } & 5 & $50 \%$ & 5 & $50 \%$ & \multirow{2}{*}{1} & \multirow{2}{*}{ NS } \\
\hline G2 & 2 & $20 \%$ & 8 & $80 \%$ & & & 6 & $60 \%$ & 4 & $40 \%$ & & \\
\hline G1 & 5 & $50 \%$ & 5 & $50 \%$ & \multirow{2}{*}{0.033} & \multirow{2}{*}{$\mathrm{S}$} & 5 & $50 \%$ & 5 & $50 \%$ & \multirow{2}{*}{0.033} & \multirow{2}{*}{$\mathrm{S}$} \\
\hline G3 & 10 & $100 \%$ & 0 & $0 \%$ & & & 10 & $100 \%$ & 0 & $0 \%$ & & \\
\hline G2 & 2 & $20 \%$ & 8 & $80 \%$ & \multirow{2}{*}{0.001} & \multirow{2}{*}{$\mathrm{S}$} & 6 & $60 \%$ & 4 & $40 \%$ & \multirow{2}{*}{0.087} & \multirow{2}{*}{ NS } \\
\hline G3 & 10 & $100 \%$ & 0 & $0 \%$ & & & 10 & $100 \%$ & 0 & $0 \%$ & & \\
\hline
\end{tabular}

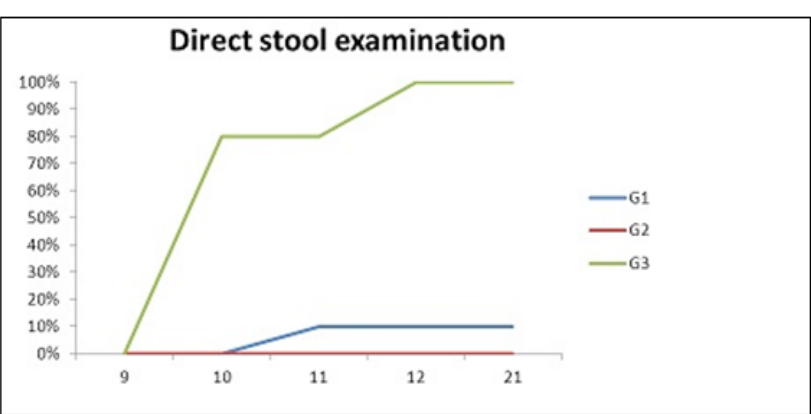

Fig. 1: Percentages of infected mice using direct stool examination through days $9,10,11,12$ and 21 .

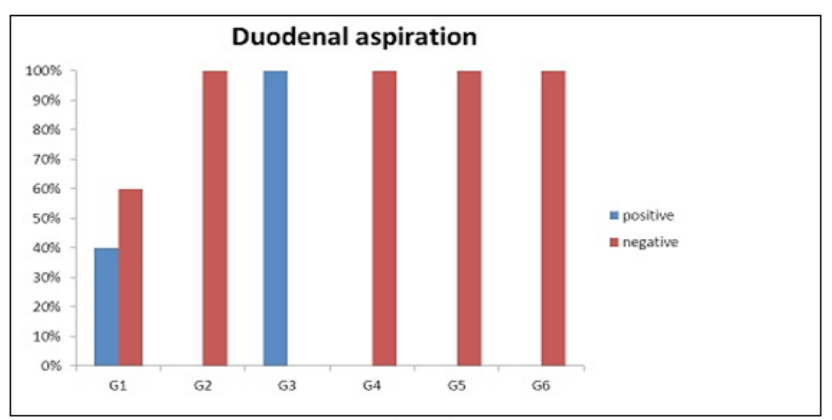

Fig. 2: Percentages of infected mice using duodenal aspiration examination through days $9,10,11,12$ and 21 . 


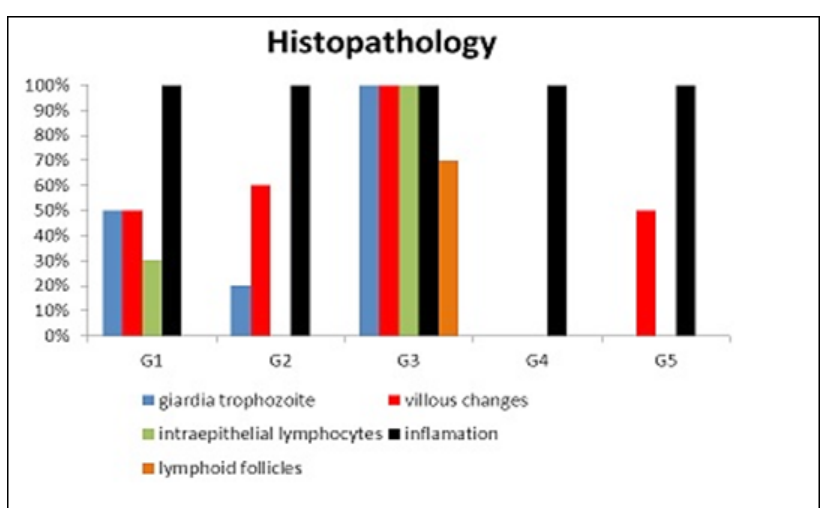

Fig. 3: Percentages of infected mice showing histopathological changes in the intestines of study groups

\section{DISCUSSION}

The present study is an attempt to determine the efficacy of radioactive cobalt- 60 and $254 \mathrm{~nm}-\mathrm{UV}$ irradiation on infectivity of $G$. lamblia cysts to mice. Results showed that experimental irradiation of Giardia cysts with cobalt-60 at a dose of $0.25 \mathrm{KGy}$ (group 1) decreased infectivity to $50 \%$ in comparison to $100 \%$ infectivity in non-irradiated group (group 3) as observed by histopathological examination. Lenaghan and Sundermann ${ }^{[45]}$ studied the effect of variable doses of the radioactive cobalt-60 on the Giardia trophozoites and concluded that a dose of more than $5 \mathrm{KGy}$ is sufficient to inactivate the trophozoites and render them unable to recover. Another study found that Giardia cysts exposed to a dose of $2.0,1.0,0.75,0.5,0.46$, or $0.25 \mathrm{KGy}$ were not infective to gerbils ${ }^{[46]}$. Also, El-Rifaey et al. ${ }^{[7]}$ studied the effectiveness of radioactive cobalt-60 in the inactivation of $G$. lamblia cyst in prevention of infection and concluded that radioactive cobalt-60 at a dose of 0.25 KGy can be used as a control measure to prevent infectivity and as a method of water treatment.

Results of our study showed that UV irradiation using wave length $254 \mathrm{~nm}$ reduced the infectivity of cysts to $20 \%$. This was determined by histopathological examination of mice small intestines on day 21 post-infection. In accordance, Campbell and Wallis ${ }^{[36]}$ reported that 254 nm UV irradiation successfully inactivated Giardia cysts at $4^{\circ} \mathrm{C}$ after 21 days. Also, Mofidi et al. ${ }^{[47]}$ recorded the same results using two different strains, G. lamblia and G. muris, with UV dosages (ranging from 0.4 to $9.8 \mathrm{~mJ} / \mathrm{cm}^{2}$ ). Shin et al. ${ }^{[48]}$ found that $G$. lamblia cysts were very sensitive to UV irradiation. One year later, the same investigators attempted reactivation of these UV exposed Giardia cysts and recorded no evidence of reactivation ${ }^{[49]}$. dos Santos et al. ${ }^{[50]}$ studied the effect of infection of $\mathrm{BALB} / \mathrm{c}$ mice by cysts exposed to UV radiation dose $25-30 \mathrm{~mJ} \mathrm{~cm}^{2}$ and found that the mice released a lower concentration of cysts in their stool than those inoculated with non-irradiated cysts. Recently, it was proved that UV radiation at $10 \mathrm{~mJ} \mathrm{~cm} 2$ can kill Giardia cysts effectively ${ }^{[51]}$.

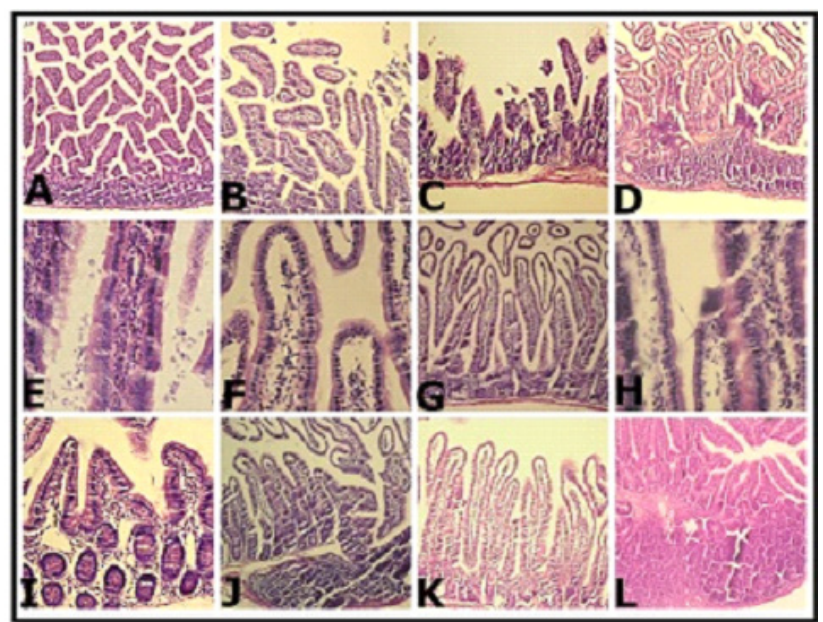

Fig. 4: Histopathological examination of mice intestines. Group 6: Non-infected control group that received non-treated water shows normal intestine (A, H \& E x100). Group 3: Infected with non-irradiated Giardia shows variable degrees of villus changes (B, C, H \& E x 100), inflammation (D, H \& E x100) and intensity of colonization $+++(\mathbf{E}, \mathrm{H} \& \mathrm{E} \mathrm{x} 400)$. Group 1: Irradiation with Cobalt 60, decreased the intensity of colonization to ++ (F, H \& E x400), decreased inflammation and preserved villi (G, H \& E x100). Group 2: Irradiation with UV rays decreased the intensity of colonization to $+(\mathbf{H}, \mathrm{H} \& \mathrm{E} x 400)$, but UV rays didn't significantly decrease villus damage (I, H \& E x100) or inflammation (J, H \& E x100). Group 4: Non-infected control group received Cobalt 60. Group 5: Non-infected control group received UV; Cobalt 60 and UV didn't significantly damage the intestinal villi $(\mathbf{K}, \mathbf{L})$, however, Cobalt 60 (K, H \& E x100) elicited lower inflammatory response than $\mathrm{UV}$ rays $(\mathbf{L}, \mathrm{H} \& \mathrm{E}$ $\mathrm{x} 100$ ).

Histopathological findings in our study demonstrated that radioactive cobalt- 60 and $254 \mathrm{~nm}-\mathrm{UV}$ irradiation treatments are effective disinfection methods against G. lamblia. Both of them efficiently reduced the infectivity of $G$. lamblia cysts. UV irradiation treatment proved to be a more powerful disinfection method than cobalt-60, having controlled the rate of infection and intensity of colonization more than the latter. However, cobalt-60 modified the virulence of the organism while preserving the mucosal architecture in the infected mice. The rays of UV, to some extent, degraded the intestinal villi more frequently than cobalt- 60 . This difference was statistically insignificant. Although both techniques apparently did not damage the intestinal villi, the UV irradiated cysts elicited a higher inflammatory response than the cobalt- 60 irradiated ones. These considerations should be borne in mind when choosing the method of disinfection pending that safety issues and cost-effectiveness allow it.

In conclusion, this study demonstrated that low dose radioactive cobalt- 60 and UV irradiation at $254 \mathrm{~nm}$ may be considered as a mean of water treatment and to prevent G. lamblia infection. Further studies are recommended to assess the effectiveness of water irradiation using both UV and cobalt-60 gamma rays together. Smaller doses of each may be tested to gain advantages of UV in irreversible damage of Giardia DNA and the less inflammatory changes associated with cobalt-60. 
Authors contribution: All authors contributed in study design, collection of materials, methodology, writing the manuscript and revising it.

Funding: This research did not receive any specific grant from funding agencies in the public, commercial, or not-for-profit sectors.

Conflict of interest: No conflicts of interest.

\section{REFERENCES}

1. Harba NM, Rady AA, Khalefa K. Evaluation of flow cytometry as a diagnostic method for detection of Giardia lamblia in comparison to IFAT and other conventional staining techniques in fecal samples. PUJ 2012; 5(2): 165-174.

2. Khalifa AM, Ibrahim IR, Said DE, Abdel-Aleem EA, Nabil RA. Cryptosporidium and Giardia in water in Alexandria: detection and evaluation of viability by flow cytometry and different stains. PUJ 2011; 4(2): 155-164.

3. Hussein AH, Rashed SM, El-Hayawan IA, Ali NS, Abou Ouf EA, Ali AT. Intestinal parasite infections and accuracy of direct thin and thick smear, formolether sedimentation, centrifugal flotation, and miniflotac techniques among patients with gastrointestinal tract disorders from the greater Cairo region, Egypt. Am J Trop Med Hyg 2017; 96(3): 589-594.

4. Gendrel D, Treluyer JM, Richard-Lenoble D. Parasitic diarrhoea in normal and malnourished children. Fundam Clin Pharmacol 2003; 17:189-198.

5. Adam EA, Yoder JS, Gould LH, Hlavsa MC, Gargano JW. Giardiasis outbreaks in the United States 19712011. Epidemiol Infect 2016; 144(13): 2790-2801

6. Carpenter CR, Fayer JT, Beach MJ. Chlorine disinfection of recreational water for Cryptosporidium parvum. Emerg Infect Dis 1999; 5: 579-584.

7. El-Rifaey SA, Shoeib EY, Elnamaky AH, Kelada RM. Experimental study on the use of cobalt- 60 irradiation in the inactivation of Giardia lamblia cyst. Kasr El Aini Med J 2013; 19(2): 25-34.

8. TunTun N, KhinKhin L. Clean and cost effective industrial wastewater treatment technology for developing countries. Int J Scient Res Pub 2015; 5(12): 162-173.

9. Ivanov AI. Giardia and giardiasis. Bulg J Vet Med 2010; 13(2): 65-80.
10. Hijnen WA, Beerendonk EF, Medema GJ. Inactivation credit of UV radiation for viruses, bacteria and protozoan oocysts in water: a review. Water Res 2006; 40(1): 3-22.

11. Sundermann CA, Estridge BH. Inactivation of Giardia cyst by cobalt 60 . J Parasitol 2010; 96(2): 425-428.

12. Tauxe RV. Food safety and irradiation: protecting the public from food borne infections. J Emerg Infect Dis 2001; 7(3): 516-521.

13. Song CC, Duan YF, Shou GC, Zhu H. Effect of cobalt-60 irradiation on the infectivity of Paragonimus westermanii metacercariae. J Parasitol 1992; 78(5): 869-871.

14. Chai JY, Kim SJ, Kook J, Lee SH. Effects of gammairradiation on the survival and development of Metagonimus yokogawai metacercariae in rats. Kor J Parasitol 1995; 33(4): 297-303.

15. Gilbert JM, Fuller AL, Scott TC, McDougald LR. Biological effects of gamma-irradiation on laboratory and field isolates of Eimeria tenella (Protozoa; Coccidia). Parasitol Res 1998; 84(6): 437-441.

16. Dubey JP, Thayer DW, Speer CA, Shen SK. Effect of gamma irradiation on unsporulated and sporulated Toxoplasma gondii oocysts. Int J Parasitol 1998; 28(3): 369-375.

17. Pai HH, Liu CS, Chen ER. The growth effects of gamma-ray irradiation on third-stage larvae of Angiostrongylus cantonensis in snail. Kaohsiung J Med Sci 2001; 17(3):120-125.

18. Flores-Pérez I, Fragoso Gonzalez G, Sciutto E, de Aluja AS. Apoptosis induced by gamma irradiation of Taenia solium metacestodes. Parasitol Res 2003; 90(3): 203-208.

19. Park GM, Yong TS. Effects of gamma-irradiation on the infectivity and chromosome aberration of Clonorchis sinensis. Kor J Parasitol 2003; 41(1): 41-45.

20. Lee SU, Joung M, Nam T, Park WY, Yu JR. Quantitative evaluation of infectivity change of Cryptosporidium parvum after gamma irradiation. Kor J Parasitol 2009; 47(1): 7-11.

21. deSouza GS, Rodrigues LA, de Oliveira WJ, Chernicharo CA, Guimarães MP, Massara CL et al. Disinfection of domestic effluents by gamma radiation: effects on the inactivation of Ascaris lumbricoides eggs. Water Res 2011; 45(17): 5523-5528. 
22. Vieira HGS, Grynberg P, Bitar M, Pires SD, Rio HOH, Macedo AM et al. Proteomic analysis of Trypanosoma cruzi response to ionizing radiation stress. PLoS ONE. 2014; 9(5): e97526.

23. Alam-Eldin YH, Badawy AF. Destructive effect of gamma irradiation on Echinococcus granulosus metacestodes. Parasitol Res 2015; 114(8): 3145-3150.

24. Hoyer O. Water disinfection with UV radiation requirements and realization. In: Proceedings of the European Conference UV Karlsruhe, UV radiation. Effects and Technologies 2004; 22-24.

25. Yaun BR, Summer SS, Eifert JD, Marcy JE. Inhibition of pathogens on fresh produce by ultraviolet energy. Int J Food Microbiol 2004; 90: 1-8.

26. Cardo LJ, Salata J, Mendez J, Reddy H, Goodrich $\mathrm{R}$. Pathogen inactivation of Trypanosoma cruzi in plasma and platelet concentrates using riboflavin and ultraviolet light. Transfus Apher Sci 2007; 37(2): 131-137.

27. Tonnetti L, Thorp AM, Reddy HL, Keil SD, Doane SK, Goodrich RP et al. Reduction of Leishmania donovani infectivity in whole blood using riboflavin and ultraviolet light. Transfusion 2015; 55(2): 326-329.

28. Hayes J, Kirf D, Garvey M, Rowan N. Disinfection and toxicological assessments of pulsed UV and pulsedplasma gas-discharge treated-water containing the waterborne protozoan enteroparasite Cryptosporidium parvum. J Microbiol Methods 2013; 94(3): 325-337.

29. Bao X, Li Q, Hua J, Zhao T, Liang W. Interactive effects of elevated ozone and UV-B radiation on soil nematode diversity. Ecotoxicology 2014; 23: 11-20.

30. Kannan G, Prandovszky E, Steinfeldt CB, Gressitt $\mathrm{KL}$, Yang C, Yolken RH et al. One minute ultraviolet exposure inhibits Toxoplasma gondii tachyzoite replication and cyst conversion without diminishing host humoral-mediated immune response. Exp Parasitol 2014; 145: 110-117.

31. Kim JS, Son Y, Bae MJ, Lee SS, Park SH, Lee HJ et al. Continuous exposure to low-dose-rate gamma irradiation reduces airway inflammation in ovalbumininduced asthma. PLoS One 2015; 10(11): e0143403.

32. Koca T, Aydın A, Sezen D, Başaran H, Karaca S. Painful plantar heel spur treatment with Co-60 teletherapy: factors influencing treatment outcome. Springerplus. 2014; 3: 21.
33. Helmy MM, Tomb JW. Concentration techniques for protozoa. Trans Roy Soc Trop Med Hyg 1931; 25: 181-185.

34. Roberts-Thomson JC, Stevens DP, Mahmoud AF, Warren KS. Giardiasis in mice-an animal model. Gastroenterol 1976; 71: 571-576.

35. Faiz. M.K. and John. P.G. Measurement of absorbed dose. In Physics of Radiation Therapy. J. W. Pine and E. Moyer (eds). Lippincott Williams and Wilkins, Philadelphia, USA. 1993, pp. 97-131.

36. Campbell AT, Wallis P. The effect of UV irradiation on human-derived Giardia lamblia cysts. Water Res 2002; 36: 963-969.

37. Visvesvara GS., Dickerson JW, Healy GR. Variable infectivity of human-derived Giardia lamblia cysts for mongolian gerbils (Meriones unguiculatus). J Clin Microbiol 1988; 5: 837-841.

38. Li D, Craik SA, Smith DW, Belosevic M. Comparison of levels of inactivation of two isolates of Giardia lamblia cysts by UV Light. App Environ Microbiol 2007; 73(7): 2218-2223.

39. Juan CJ, Josette F, Colette C, Laurence F, Jean-Marie G, Monique C, Eduardo D. Antibody and cytokine responses to Giardia excretory/secretory proteins in Giardia intestinalis-infected BALB/c mice. Parasitol Res 2014; 113: 2709-2718.

40. Finch GR, Black CW, Labatiuk CW, Gyurek L, Belsovic M. Comparison of Giardia lamblia and Giardia muris cyst inactivation by ozone. App Environ Microbiol 1993; 86: 1228-1234.

41. Frank W, Schaefer II, Clifford HJ, Chyi HH, Rice EW Determination of Giardia lamblia cyst infective dose for the mongolian gerbil (Meriones unguiculatus). App Environ Microbiol 1991; 57(8): 2408-2409.

42. Culling CFA. Handbook of histopathological technique $1^{\text {st }}$ ed. London: Bulterworth and Co ltd. 1957: 304.

43. Bancroft JD. Histochemical techniques. $2^{\text {nd }}$ ed. London and Boston: Bulterworth and Co ltd. 1975: 86-78.

44. Oberhuber G, Stolte M. Giardiasis: Analysis of histological changes in biopsy specimens of 80 patients. J Clin Pathol 1990; 43(8): 641-643.

45. Lenaghan S, Sundermann C. Effect of varying cobalt 60 doses on survival and growth of Giardia lamblia trophozoites. J Eukaryot Microbiol 2003; 50(suppl): 701 
46. Sundermann CA, Estridge BH. Inactivation of Giardia cyst by cobalt 60 . J Parasitol 2010; 96(2): 425-428.

47. Mofidi AA, Meyer EA, Wallis PM, Chou CI, Meyer $\mathrm{BP}$, Ramalingam $\mathrm{S}$ et al. The effect of UV light on the inactivation of Giardia lamblia and Giardia muris cysts as determined by animal infectivity assay (P-2951-01). Water Res 2002; 36: 2098-2108.

48. Shin GA, Linden KG, Faubert G. Inactivation of Giardia lamblia cysts by polychromatic UV. Lett App Microbiol 2009; 48(6): 790-792.
49. Shin G, Linden KG, Faubert G. Reactivation of Giardia lamblia cysts after exposure to polychromatic UV light. Lett App Microbiol 2010; 51(4): 395-399.

50. dos Santos LU, Alves DP, Ana Maria Aparecida Guaraldo AA, Neto RC, Durigan M, Franco RM. Infectivity of Giardia duodenalis cysts from UV light-disinfected wastewater effluent using a nude BALB/c mouse model. ISRN Parasitol 2013 doi: 10.5402/2013/713958. eCollection:1-7

51. Einarsson E, Svärd SG, Troell K. UV irradiation responses in Giardia intestinalis. Exp Parasitol 2015; 154: $25-32$. 